\title{
SOME MOVEMENTS OF RING-BILLED GULLS COLOR-MARKED IN COLORADO
}

\author{
by Ronald A. Ryder, Fort Collins, Colorado
}

The Ring-billed Gull (Larus delawarensis) is one of the most common gulls which migrates through central Colorado, but until recently the breeding and wintering areas of these particular migrants have not been known. Apparently a few Ring-bills nested in Colorado in the late 1890's, but there are no recent nestings known. A few non-breeders remain in the vicinity of reservoirs north of Denver throughout the summer, where also some Ring-bills can be found even in the coldest winters. However, most Ring-bills are migrants merely passing through the state, presumably to nest in Canada and winter in Mexico.

Since the fall of 1962 , my students and I have captured, banded, dyed and released various species of gulls on and near Timnath Reservoir, about six miles southeast of Fort Collins. This lies east of the Rocky Mountains in flat to rolling prairie farmland at an elevation of about 4,900 feet. Timnath Reservoir is typical of many artificial impoundments in the North Platte River Drainage. It is primarily for irrigation storage but also supports a high population of carp ( $C y p$ rinus carpio), which have been seined intermittently by commercial fishermen. Frequently, under-sized carp are left dead on the beaches. These we have used as bait to lure gulls in front of a cannon-projected net such as has been employed in many parts of North America to capture waterfowl. From September 1962 to June 1965, we captured over 400 Ring-billed Gulls in numbers ranging from one or two at a time to as many as 71 in one catch. Most of these gulls were dyed a brilliant yellow with a harmless dye composed of picric acid, alcohol and water. All were banded with standard aluminum bands provided by the U.S. Fish and Wildlife Service. In many cases various colored bands were also used to indicate specific banding periods. During the fall of 1962 some gulls were also marked with plastic neck tags.

To date, many of these color-marked Ring-billed Gulls have been sighted and reported by co-operators from Mexico to Canada. A brief note in the Blue Jay (23:84) resulted in an encouraging response from Saskatchewan. Several banded gulls have also been reported as shot or found dead. From these various reports we now have a fairly good idea where these Colorado migrants winter and breed, as well as knowing some of the feeding areas en route (see Fig. 1).

Apparently, many of these gulls winter in western Mexico along the Gulf of California, while others have been seen in southern Colorado and northern Arizona, probably en route to this wintering area. Others seem to pass through southeastern New Mexico, but as yet no sightings or recoveries have been reported from the Texas coast or eastern Mexico. A few dyed gulls have been seen in Colorado throughout the winter, although most seem to leave the state by midNovember. Some idea of the fairly leisurely pace of this southward movement is indicated by a few of the sightings. One dyed gull was seen near Flagstaff, Arizona, October 30, 1963, approximately 25 days after it was released in Colorado, while another reached the Gulf of California in Sonora, Mexico, by at least November 12, 1962, perhaps two months after banding. Evidence of wandering seems indicated by one dyed gull that was found injured in Oklahoma City on December 16, 1963, a month and a half after it was banded. This or another "yellow" gull was reported several times previously in the same general area prior to this recovery. 


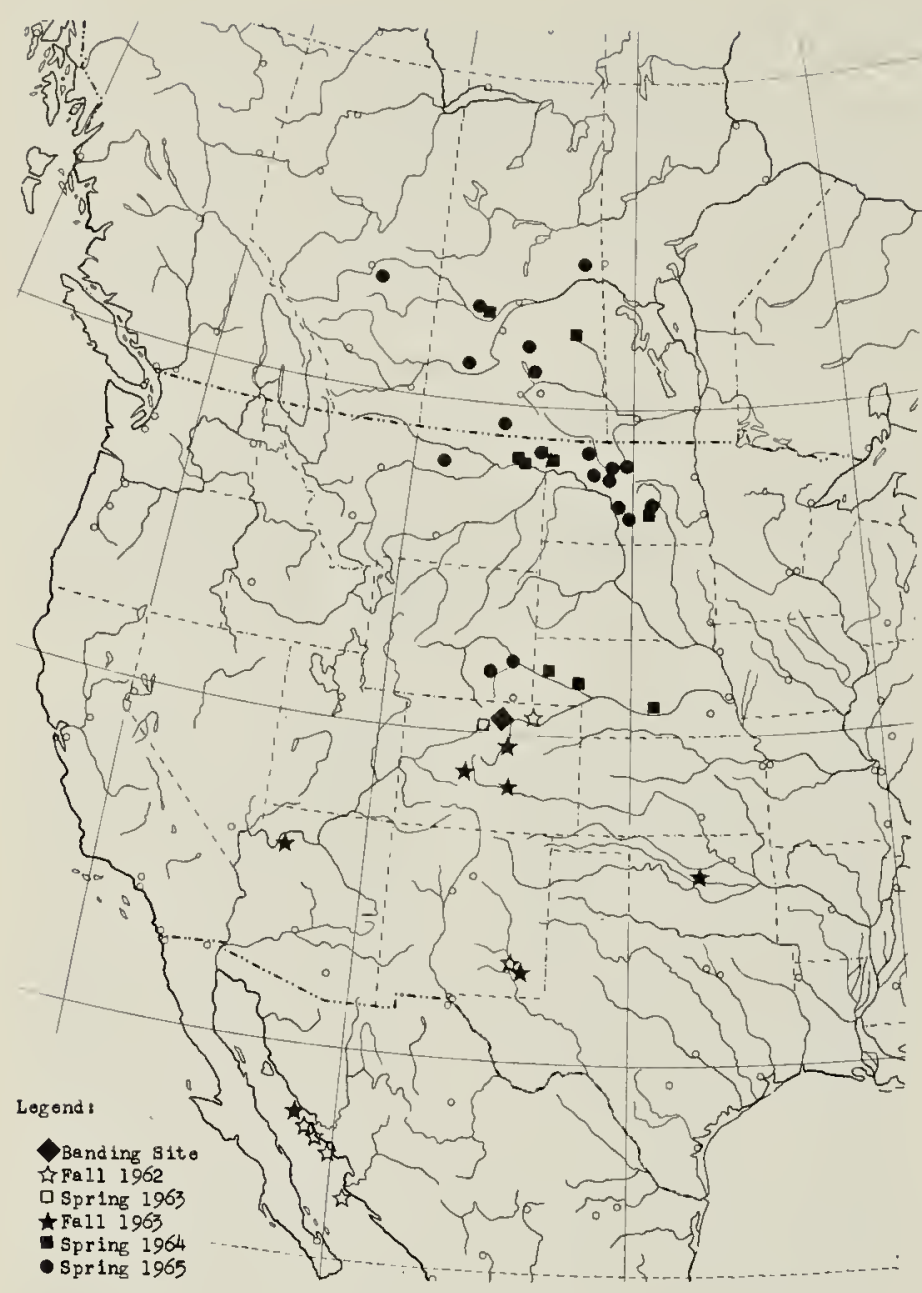

Figure 1-Locations where dyed Ringbilled Gulls have been sighted. (Omits numerous reports within 50 miles of the banding site.)
Ring-billed Gulls migrating through Colorado are now known to breed in at least two definite locations, one in Saskatchewan and one in Montana. One immature gull which we caught near Fort Collins on October 8, 1963, had been banded as a nestling on June 27,1963 , in a colony on Redberry Lake, Saskatchewan, by Dr. C. Stuart Houston. In the 1964 nesting season Dr. Houston observed one of our "yellow" Ring-bills feeding young in the same colony and in 1965 found a well-kept, recently lost, picric-acidcolored gull feather there also. In Montana, Refuge Manager R. R. Hoffman reported one of our yellowdyed gulls incubating three eggs on a small island at Bowdoin National Wildlife Refuge on June 2, 1965. Other dyed Ring-bills have been reported during the breeding season elsewhere in Montana and Saskatchewan, as well as in Alberta and North Dakota (Fig. 1).

Observations of dyed gulls at locations between the banding site and breeding areas are fewer than those reported locally in Colorado or in pos-

TABLE 1-Sightings or recoveries of Ring-billed Gulls dyed and banded near Fort Collins, Colorado.

Place Seen

Colorado

New Mexico

Arizona

Oklahoma

Mexico

Nebraska

North Dakota

Wyoming

Montana

Saskatchewan

Alberta

Total reports

Maximum number any one report

Total birds possible ${ }^{1}$

\begin{tabular}{|c|c|c|c|c|}
\hline Fall & Spring & Fall & Spring & Spring \\
\hline 1962 & 1963 & 1963 & 1964 & 1965 \\
\hline 50 & 21 & 73 & 2 & 59 \\
\hline 1 & - & 1 & 一 & - \\
\hline - & - & 1 & - & - \\
\hline- & - & 1 & - & - \\
\hline 4 & - & 1 & - & - \\
\hline 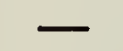 & 一 & - & 3 & - \\
\hline & 一 & - & 2 & 9 \\
\hline 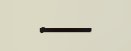 & - & - & - & 2 \\
\hline & - & - & 2 & 2 \\
\hline- & - & - & 2 & 6 \\
\hline & 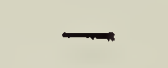 & - & 一 & 1 \\
\hline 55 & 21 & 77 & 11 & 79 \\
\hline 8 & 2 & 9 & 1 & 7 \\
\hline 112 & 65 & 101 & 49 & 80 \\
\hline
\end{tabular}

${ }^{1}$ Assuming dye retention of three to four months. 
sible breeding areas in the northern Great Plains. At least in the spring of 1964, dyed Ring-bills were seen following plows in fields in western Nebraska about two weeks after being released in Colorado. Similar sightings were reported in southeastern Wyoming in the spring of 1965 . The lack of sightings reported in South Dakota, northern Wyoming and southeastern Montana is probably influenced by the fact that there are relatively few observers in those areas, but it may indicate that few of our marked gulls stopped in those areas.
As might be expected, most of our observations in both spring and fall have been in north-central Colorado (Table 1), where undoubtedly more people were aware of our studies, and where the gulls had not yet lost much of the dye either by moulting or fading. Most dyed gulls retained fairly good coloring for three to four months, although we had a few recognizable as long as six months. Two gulls with neck tags were observed in normal white plumage in the fall of 1963 , almost one year following initial banding.

\title{
UNUSUAL ACCIDENT INVOLVING A CALIFORNIA GULL
}

\author{
by Spencer G. Sealy, Battleford
}

Colonial birds are confronted with many dangers. A predator may drastically reduce the number of young gulls in a colony, rising water levels may flood a "gull island", or young birds may be killed in falling off a ledge, or become permanently wedged in a crevice. One or more of these dangers are usually present as factors limiting the population of each colony. This note describes an unusual type of accident involving an adult California Gull (Larus californicus) on "Bird Island" in Lake Newell, 20 miles south of Brooks, Alberta. This island, about 500 yards long and 100 yards wide, lies in an east-west direction, with its south-facing side gradually sloping into the water, while its north-facing side, which drops abruptly, is undergoing water erosion.

While banding California Gulls and Doubl e-crested Cormorants (Phalacrocorax auritus) on June 19, 1965, C. A. Gordon, J. P. Ryder, J. A. Wolford and I discovered a gull partially covered by earth which had fallen from the eroded north-facing side of this island (see photograph). Only the bird's head, neck and one wing protruded, rendering it completely helpless. The bird was subse- quently removed, found to be in a very weak state, and released on the island. It is not known whether it survived. Later it was found that many young gulls sought refuge at the base of this eroded bank, thus rendering them vulnerable to a similar accident; however, no juvenile mortalities resulting from this type of accident were discovered. It is possible that falling earth may have completely covered some of the young, making them impossible to be seen without excavation.

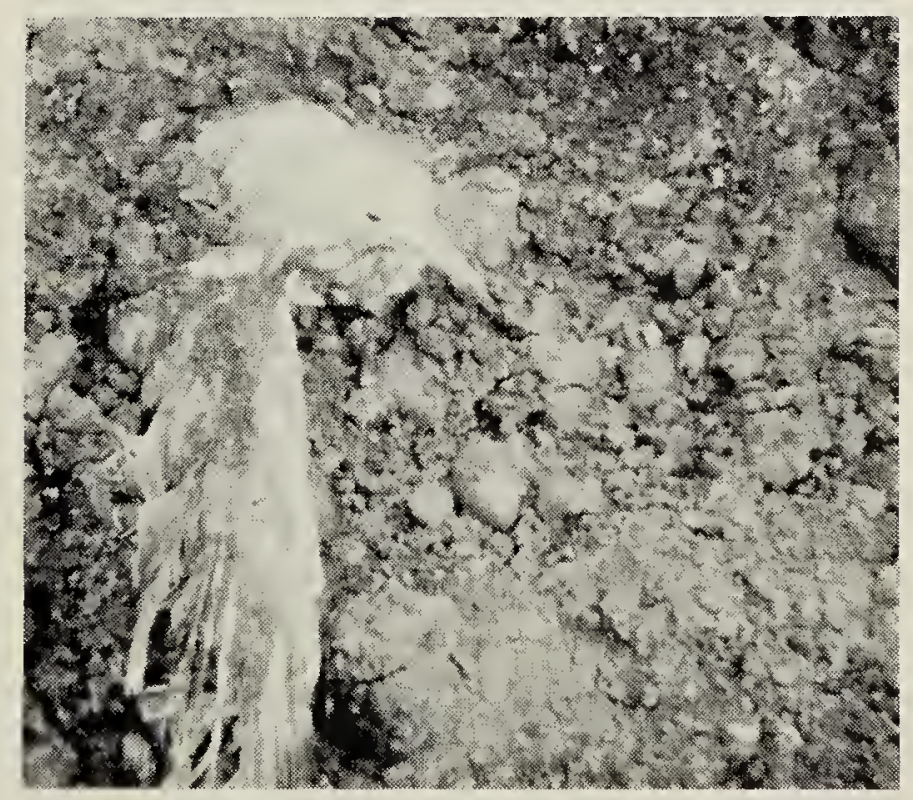

Photo by S. G. Sealy 